\title{
Proses Pembangunan Smart City di Indonesia Menggunakan Metode Big Data Analystis Dalam Penerapan E-Commerce
}

\author{
Sri Mahrani ${ }^{1}$, Ira Daniah Pasi ${ }^{2}$, Andi Karina Mutmainnah ${ }^{3}$, Sri Wulan Purnama Samosir ${ }^{4}$,Indra Gunawan ${ }^{5}$ \\ 1,2,3,4,5 STIKOM Tunas Bangsa Pematangsiantar \\ ${ }^{1}$ Srimaharani2000@gmail.com, ${ }^{2}$ iradaniapasih900@gmail.com, \\ 3 andikarinamutmainnahxxx@gmail.com, ${ }^{4}$ sriwulanpurnamasamosir@gmail.com, \\ 5indra@amiktunasbangsa.ac.id
}

\begin{abstract}
Industry 4.0 in Indonesia is currently the fourth level that is commonly used today. Everything has relied on digital technology or from the first technological stage to the 4th stage which is now what is called the 4.0 revolution era. Currently, the development of a smart city or smart city where big cities in Indonesia are using the concept. But smart mobility is not only about technology, we also have to maintain the comfort and safety of people who want to use one of the smart city concepts. The method used is big data analysis where we can find out by extracting information. By analyzing various types of large data sets that can be viewed from the internet using technology. Big Data Analytics is very useful in the implementation of E Commerce. Because during the Covid-19 pandemic, e-commerce is urgently needed in building a smart city in Indonesia, especially in public transportation, which is currently having a high production increase. However, this method only emphasizes the processing of large data and how to apply the data using Big Data Analytics.
\end{abstract}

Keywords: Big Data Analystic, E Commerce, Smart City, Big Data

\begin{abstract}
Abstrak
Industri 4.0 di Indonesia saat ini adalah tingkatan keempat yang umum digunakan pada zaman ini. Segala sesuatunya sudah mengandalkan teknologi digital atau dari tahapan teknologi pertama hingga sampai tahapan ke 4 yang sekarang ini itulah yang dinamakan dengan era revormasi 4.0. Saat ini tengah berkembangnya smart city atau kota cerdas dimana kota-kota besar diindonesia sedang menggunakan konsep tersebut. Namun mobilitas cerdas bukan hanya tentang teknologi saja kita juga harus menjaga kenyamanan dan keamanan orang yang ingin menggunakan salah satu konsep smart city tersebut. Metode yang digunakan adalah big data analystis dimana kita dapat menemukan dengan cara penggalian informasi. Dengan menganalisis berbagai jenis kumpulan data yang berukuran besar dan dapat dilihat dari internet dengan menggunakan teknology. Big Data Analystic sangat berguna dalam penerapan E Commerce. Karena di masa pandemi Covid- 19 sangat dibutuhkannya E Commerce dalam membangun smart city di indonesia, terutama pada sebuah proses pembayaran yang dilakukan secara online. Namun dalam metode tersebut hanya menegaskan pada pengolahan data yang besar dan cara pengaplikasian data menggunakan Big Data Analystic.
\end{abstract}

\section{Kata Kunci : Big Data Analystic, E Commerce, Smart City, Big Data}

\section{PENDAHULUAN}

Data memiliki peran penting dalam pengambilan keputusan strategi terutama ketika memasuki era ledakan data/data besar (big data), dimana perusahaan-perusahaan dalam berbagai sektor diharuskan menangani sejumlah data besar (big data), hal ini dikarenakan data yang besar (big data) dapat menawarkan wawasan yang sangat berharga selain itu juga menawarkan keunggulan kompetitif jika sumber daya teknologi dan organisasi mendukung mereka (Morabito, 2015). Oleh karena itu pihak-pihak yang mampu mengolah dan memanfaatkan data-data yang tersedia dalam volume besar, cepat berubah, keragaman variatif, dan komplekstas yang tinggi serta kecepatan penambahan data yang tinggi dapat mengambil keuntungan yang besar dengan mengacu pada manfaat besar yang ditawarkan oleh teknologi big data. Namun sayangnya penerapan big data analytics masih belum begitu populer di Indonesia.

Saat ini semakin meningkatnya peluang usaha dalam bisnis apalagi pada jaman saat ini sudah memasuki era revolusi dimana semua dilakukan menggunakan teknologi dari pengolahan data dan cara melihat data- data besar perusahaan. Maka para pengusaha yang menitis karir harus lebih memikirkan cara tercepat dalam memajukan peluang bisnis mereka dan cara mencari data data penting yang mungkin harus dilakukan dengan cepat dalam waktu yang singkat. Big data analitis adalah salah satu cara yang dapat digunakan oleh para peluang usaha E- comerce dalam memajukan usaha mereka. Dan cara 
kerja ini lah salah satu cara dalam proses pembangunan smart city dari cara pencarian data.

Para praktisi yang melakukan studi tentang big data analytics menekankan perlunya memahami bagaimana, mengapa dan kapan aplikasi big data analytics (BDA) dapat menjadi sumber yang sangat berharga bagi perusahaan untuk mendapatkan keunggulan kompetitif (Abbasi, Sarker, \& Chiang, 2016; Agarwal \& Dhar, 2014; dan Corte Real, Oliveira \& Ruivo, 2014)._Meskipun teknologi big data analytics telah diakui sebagai hal besar setelah inovasi (yaitu merupakan sumber potensial nilai bisnis dan keunggulan kompetitif), namun rantai nilai big data analytics relatif belum terjamah dan perlu diselidiki lebih lanjut. Menurut Abbasi et al (2016), masih belum ada penelitian empiris yang menilai bagaimana big data analytics dapat membawa nilai bisnis (business value) bagi perusahaan. Selain itu menurut Corte Real et al (2014), belum ditemukan penelitian tentang bagaimana big data analytics dapat membangun hubungan antara aset pengetahuan, kelincahan organisasi dan kinerja (tingkat proses dan keunggulan kompetitif).

Meskipun literature potensi bisnis big data analytics berkembang pesat, namun dalam studi empiris teori big data terbatas hanya digunakan dalam domain nilai bisis IT (Gupta \& George, 2016).Menurut Constantiou \& Kallinikos (2015), untuk memperoleh implikasi teoritis dan praktek serta untuk memahami area penelitian dimasa depan, kiranya penting untuk menempatkan studi saat ini dalam kerangka kerja penelitian dan memahami bagaimana artefak inti dibentuk serta bagaimana mengarahkanhya ke business value.

Chrisvania (2017), menyatakan bahwa big data yang diimplementasikan oleh perusahaan besar umumnya digunakan secara multi fungsi, dengan implementasi ini analisa baru digunakan untuk suatu kepentingan tanpa mengubah infrastruktur yang sudah mereka bentuk secara signifikan. Namun bagi perusahaan menengah atau SME (small medium entreprise) mereka mengimplementasi big data untuk menganalisis suatu keperluan tertentu secara spesifik atau terperinci.

Big data diperkenalkan pertama kali oleh O'Reilly Media pada tahun 2015. Sebagian besar definisi big data fokus pada ukuran data dalam penyimpanan. Atribut penting dari big data selain ukuran adalah sebagai berikut:

\section{Volume data}

2.Variasi data

\section{Kecepatan}

3V big data merupakan definisi yang komprehensif dan mereka menggagalkan mitos bahwa data besar hanya tentang volume data, selain itu masing-masing dari $3 \mathrm{~V}$ memiliki konsekuensi tersendiri untuk analitik (Russom,
2011). Sedangkan menurut data Chandarana, Parth, \& Vijayakakshmi (2014), big mengacu pada 3V yaitu volume, variety, velocity dan ada yang menambahkan unsur V lainnya seperti veracity dan value. Volume (kapasitas data) berkaitan dengan ukuran media penyimpanan data yang sangat besar atau mungkin tidak terbatas hingga satuan petabytes atau zettabytes.

Tujuan dari pembahasan ini adalah untuk memberikan pengetahuan kepada pembaca bahwa pentingnya mengetahui tentang kelebihan dan kekurangan dari big data pada pembangunan smart city di era revormasi 4.0 ini. Dimana sekarang ini Indonesia sangat tertinggal dengan negara lainnya untuk itu kita harus lebih giat lagi untuk mengembangkan negara yang kita cintai ini seperti menggunakan konsep smart city agar era revormasi 4.0 ini lebih maju lagi dan lebih berkembang lagi.

\section{METODE PENELITIAN}

Dalam hal ini metode yang digunakan adalah metode Big Data Analystic dimana data tersebut digunakan untuk menangkap data-data besar data tersebut merupakan data yang berupa informasi peningkatan sebuah produck atau bisnis pada perusahaan dalam menjualkan hasil product mereka. Sebuah tingkatan yang menginformasikan hasil penjualan dari tahun ketahun.

Berikut adalah kerangka yang digunakan :

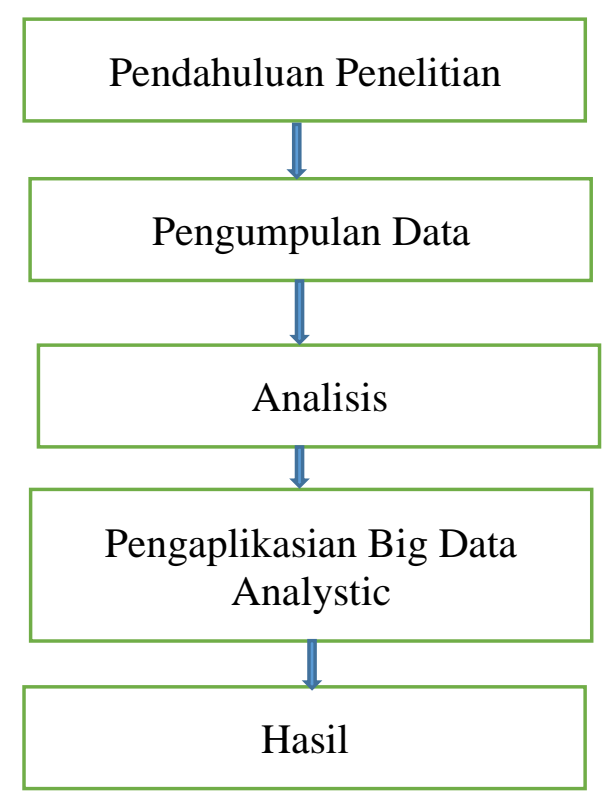

Gambar 1. Kerangka Kerja Penelitian

\subsection{Big Data Analystic}

Big data analytics adalah proses penggalian informasi yang berguna dengan menganalisis berbagai jenis kumpulan data yang berukuran besar. Big data analytics digunakan untuk menemukan pola tersembunyi, tren pasar, dan preferensi konsumen untuk kepentingan 
pengambilan keputusan suatu perusahaan. Dalam proses big data analytics, ada beberapa langkah dan teknologi yang digunakan. Pertama adalah data acquisition. Data acquisition memiliki dua komponen, yaitu identifikasi dan pengumpulan big data. Identifikasi big data dilakukan dengan menganalisis dua format data, yaitu born digital dan born analogue data. Born digital data adalah informasi yang ditangkap melalui media digital, seperti aplikasi komputer, smartphone, dan lain sebagainya. Jenis data ini memiliki jangkauan yang terus berkembang karena sistem terus mengumpulkan berbagai jenis informasi dari user. Salah satu fungsi data born digital analogue adalah dapat melacak dan memberikan informasi demografis, misalnya Cookie, Analisis Web dan pelacakan GPS. Born analogue data adalah informasi yang berupa gambar, video, dan format lain yang berhubungan dengan unsur fisik dunia. Data ini harus dikonversi ke dalam format digital dengan menggunakan sensor, seperti kamera, rekaman suara, asisten digital, dan sebagainya.

Chen, Chiang, \& Storey (2012) menciptakan istilah Big Data Analytics (BDA), yaitu terkait bisnis \& analitik (BI \& A), dimana sebagian besar teknologinya menyangkut data mining dan analisis statistik. Literatur terbaru menunjukkan bahwa ada banyak ruang untuk penelitian BDA lebih lanjut (Abbasi et al., 2016; Agarwal \& Dhar, 2014; Erevelles, Fukawa, \& Swayne, 2016). Lebih jauh Abbasi et al., 2016; Agarwal \& Dhar, 2014; Erevelles, Fukuwa, \& Swayne (2016) mengindikasikan bahwa masih banyak celah untuk penelitian-penelitian big data analytics lebih lanjut. Terkait nilai (value) sebagian besar studi akademis big data analytics fokus pada analisis nilai bisnis dari perspektif data atau sistem (LaValle et al., 2011; Kwon et al., 2014) Istilah "big data" digunakan untuk pertama kalinya pada tahun 1997 oleh Michael Cox dan David Ellsworth dalam makalah yang dipresentasikan pada konferensi IEEE yaitu memaparkan tentang visualisasi data dan tantangan yang diajukan untuk sistem komputer.

\subsection{E-Commerce}

Menurut Laudon dan Laudon (1998) E- Commerce adalah suatu proses membeli dan menjual produk - produk secara elektronik oleh konsumen dan dari perusahaan ke perusahaan dengan komputer sebagai perantara transaksi bisnis. Media yang dapat digunakan dalam aktivitas ecommerce adalah world wide web internet. Menurut Hidayat (2008:7) ada beberapa kelebihan yang dimiliki ecommerce dan tidak dimiliki oleh transaksi bisnis yang dilakukan secara offline. Proses jual-beli di sistem ecommerce yang membedakan dengan proses jual-beli tradisional adalah semua proses mulai dari mencari informasi mengenai barang atau jasa yang diperlukan, melakukan pemesanan, hingga pembayaran di lakukan secara elektronik melalui media internet. Menurut Elisabet Y. A, Ratnasari dkk, dijelaskan dalam jurnal aplikasi E - Commerce 2014. E-commerce merupakan kepanjangan dari electronic commerce yang berarti erdagangan yang dilakukan secara elektronik. Dalam buku introduction to information technology, e commerce berarti perdagangan elecreonik yang mencangkup proses pembelian, penjualan, transfer, atau pertukaran produk, layanan, atau informasi melalui jaringan komputer, termasuk internet (Turban, 2005:181).

\subsection{Smart City}

Menurut Wikipedia, smart city adalah visi pembangunan perkotaan untuk mengintegrasikan beberapa teknologi informasi dan komunikasi (ICT) dan solusi Internet of Things (IOT) dalam sebuah bentuk yang aman untuk mengelola aset kota. Berdasarkan Wikipedia, definisi dari Smart City itu begitu luas mencakup berbagai macam keseluruhan teknologi digital yang dapat meningkatkan kualitas kehidupan, mengurangi biaya dan sumber

konsumsi, dan dapat meningkatkan interaksi aktif antara kota dan warganya secara efektif._Deakin mendefinisikan kota pintar sebagai salah satu yang memanfaatkan ICT untuk memenuhi tuntutan pasar (warga kota), dan bahwa keterlibatan masyarakat dalam proses ini diperlukan untuk sebuah kota pintar. Sehingga Kota cerdas akan menjadi kota yang tidak hanya memiliki teknologi ICT di daerah tertentu, tetapi juga telah menerapkan teknologi ini dengan cara yang positif berdampak pada masyarakat setempat ( Deakin, Mark 2013).

\subsection{Big Data}

Big data pertama kali disebut dalam sebuah artikel ilmiah berjudul Application- controlled demand paging for out-of-core visualization. Yang ditulis oleh Michael Cox dan David Ellsworth tahun 1997. Persoalan yang muncul mengenai Big data dinyatakan dalam rumusan berikut: Visualization provides an interesting challenge for computer systems: data sets are generally quite large, taxing the capacities of main memory, local disk, and even remote disk. We call this the problem of big data.Di dalam perkembangan selanjutnya banyak pengertian seperti tertuang di dalam tulisan Victoria Louise Lemieux (2014), berkaitan dengan Big Data antara lain: At what volume data become big remains an open question, however, with some suggesting that it comprises data at the scale of exabytes, while others argue for zettabytes or yottabytes (Heer and Kandel, 2012). Amore formal definition of the term suggests that it is data "with sizes beyond the ability of commonly used software tools to capture, curate, manage, and process the data within a tolerable elapsed time" (Snijders et al., 2012). Other definitions emphasise not just the increasing volume or amount of data, but also its velocity (speed of data in and 
out), and variety (range of data types and sources) (Gartner, 2011).

Di dalam lingkungan organisasi juga mulai tumbuh sejumlah pegawai / staf yang secara spesifik mendapat sebutan sebagai "analis bisnis", "data analis" dan " ilmuwan data" ( Kandel et al ., 2011), yang dalam aktifitas bekerjanya memanfaatkan peralatan yang modern, melakukan praktek dan mencari solusi. Di antaranya adalah melakukan analisis visual (VA), yang didefinisikan sebagai " ilmu penalaran analitis yang difasilitasi oleh layanan antarmuka visual interaktif " Thomas dan Cook, dalam Lemieux (2014) .

\section{HASIL PENELITIAN}

\subsection{Proses Pembangunan Smart City}

Pada masa pandemi saat ini Negara Indonesia akan menciptakan sebuah kota dimana kota tersebut di permudah dengan kemampuan IT. Salah satunya adalah dengan menciptkankan lapangan pekerjaan baru bagi para masyarakat. Sudah banyak usaha kerja yang dapat dilakukan oleh masyarakat dari rumah salah satunya adalah bisnis online. E- comerce yang sudah ada di indonesia saat ini adalah :

- Shopee

- Lazada

- Blibli.com

- Aku Laku

Dari usaha online saat ini sangat mempengaruhi usaha bagi masyarakat begitu juga peluang besar ekonomi masyarakat. Apalagi saat ini para IT sudah bisa menciptakan sebuah layanan pembayaran secara online salah satunya spaylater. Spay later saat ini sudah bisa mendeteksi jumlah pinjaman para pengguna dan melakukan kalkulasi perhitungan jumlah bunga yang harus di bayar. Maka dari itu bantuan pencarian data transaksi menggunakan big data analytic untuk mencari dan memperhitungkan nominal dari pembayaran yang harus di bayar dan yang diterima.

Dari hasil yang sudah di ciptakan oleh para IT, maka ini adalah salah satu proses pembangunan smart city dengan cara mempermudah pelayanan online seluruh indonesia.

\subsection{Tools of Big Data}

Menurut Alamsyah (2015), tools yang tersedia untuk penerapan big data dapat dikategorikan menjadi 2 yaitu: berbayar (personalized software) dan tidak berbayar (berbasis open source software). Tools tersebut berkaitan dengan 4 (empat) tahapan aktivitas dan dukungan teknologi pada Big Data yang mencakup (Alamsyah, 2015):

1. Acquired, berhubungan dengan sumber dan cara mendapatkan data.

2. Accessed, berhubungan dengan daya akses data. Data yang sudah dikumpulkan memerlukan tata kelola, integrasi, storage dan computing agar dapat dikelola.

3. Analytic, berhubungan dengan informasi yang akan didapatkan, atau hasil pengelolaan data yang telah diproses. Analitik yang dilakukan dapat berupa descriptive (penggambaran data), diagnostic (mencari sebab akibat berdasar data), predictive (memprediksi kejadian dimasa depan) maupun prescriptive analytics (merekomendasikan pilihan dan implikasi dari setiap opsi).

4. Application terkait visualisasi dan reporting hasil dari analitik. Contoh application tool yang digunakan pada tahap ini yaitu R.Studio

\subsection{Big Data Analytics and Business Value}

Menurut Davenport (2006), dalam konteks big data, sangatlah penting untuk mengidentifikasi berbagai jenis sumber daya, karena keberagaman bisnis dapat menjadi sumber diferensiasi kompetitif (source of competitive differentiation). Beberapa penelitian mendefinisikan building blocks perusahaan terkait big data analytics capability adalah membangun sumber daya yang diperlukan ((McAfee et al., 2012; Kamioka \& Tapanainen, 2014; Gupta \& George, 2016; Wamba et el., 2017), namun demikian mayorita studi masih mengadopsi konsep dari literatur IT dan masih sedikit studi yang mengkhususkan pada konteks big data.

Sebagian besar penelitian saat ini masih terfragmentasi, sehingga sulit mengevaluasi nilai bisnis (business value), misal Kaisler et al (2013) melakukan identifikasi penyimpangan data dan transportasi data 
sebagai aspek penting berkaitan dengan nilai big data. Dalam penelitian ini peneliti berusaha untuk mengintegrasikan dari perspektif teoritis dan dikombinasikan dengan literature yang ada terkait big data analytics dan mengkaji lebih dalam pentingnya perusahaan mendorong kapabilitas organisasi.

\subsection{Potential Benefits of Big Data Analytics}

Saat ini organisasi yang mengadopsi big data analytics sudah dalam jumlah yang besar. Faktor penentu dari manfaat-manfaat potensial dari big data analytics adalah mendorong organisasi atau perusahaan mengadopsi big data analytics. Russom (2011) menyatakan bahwa segala bentuk keterlibatan dengan konsumen big data analytics dapat memberikan manfaat. Bisnis intelegen secara umum dapat memberi manfaat dengan menggunakan big data analytics.

Tiga alasan Shang and Seddon (2002) mengklasifikasikan potensi manfaat dari big data analytics, antara lain adalah sebagai berikut: (1) memberikan seperangkat manfaat spesifik dari sub dimensi big data analytics, yang dapat membantu mengidentifikasi manfaat perkategori, (2) kerangka kerja didesain untuk para manajer dalam menilai manfaat dari sistem enterprise perusahaan, (3) memberikan klasifikasi dan panduan yang jelas manfaat-manfaat dari sistem enterprise perusahaan. Menurut Chrisvania (2017), manfaat-manfaat yang bisa digunakan oleh perusahaan dengan mengimplementasikan big data adalah sebagai berikut, (1) analisis data sosial (social data analysis), (2) Analisis data riwayat (historical data analysis), dan (3) analisis prediksi (predictive analysis).

\section{PEMBAHASAN}

Penelitian ini melibatkan sebuah data persentase dari usaha E- Commerce menurut provinsi di indonesia, tahun 2020. Berikut adalah data persentase :

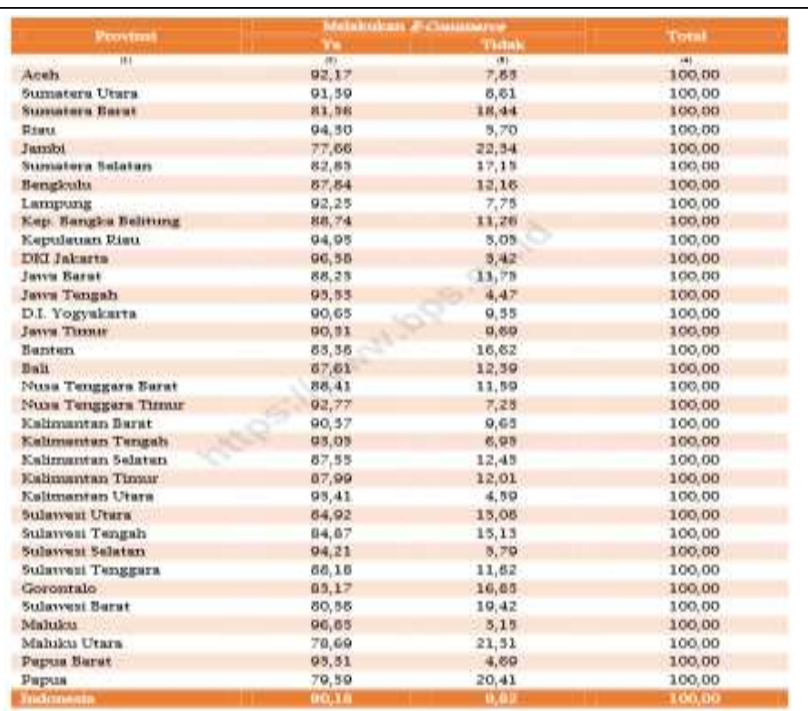

Gambar 2. Tabel data persentase usaha e-commerce Sumber : Data Pusat Statistik

Dari data di atas hasil persentase akan di lihat melalui proses Data Analysis, dan bagaimana cara pengaplikasian data tersebut menggunakan salah satuformula yaitu formula vlookap yang digunakan melalui microsoft excel. Berikut cara pengerjaan dari Big Data Analystic :

1. Klik Data - Data Validation - allow : list- source : blok seluruh data

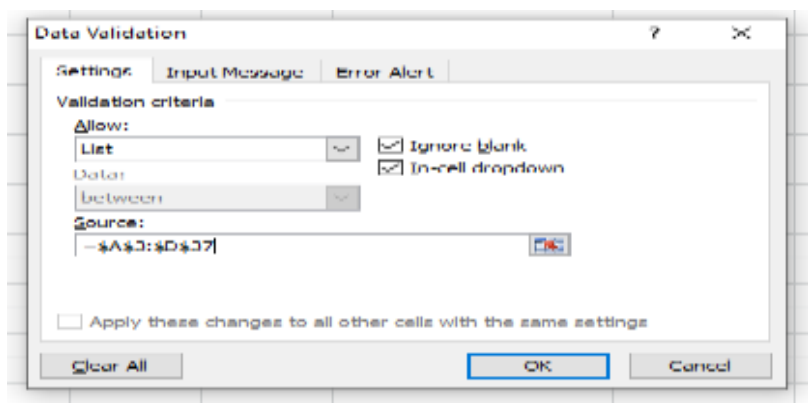

Gambar 3 Data Validation

2. Menggunakan Formula Bar dengan rumus (=Vlookup(lookup_value;table_array;col_index_num ;[range_lookup] maka akan muncul hasil data seperti ini, kami menggunakan contoh dari sumatera selatan: 
MJI Vol.13, No.2, Desember 2021, hlm. 57-63

\begin{tabular}{|c|c|c|c|}
\hline $\begin{array}{c}\text { Provinsi Melakukan } \\
\text { E-Commerce }\end{array}$ & ya & tidak & total \\
\hline & 2 & 3 & 4 \\
\hline Sumatera Selatan & 82,85 & 17,15 & 100,00 \\
\hline
\end{tabular}

Tabel. 1 Data hasil vlookup Keterangan : untuk [range_lookup] bisa pilih False

3. Munculkan hasil diagram

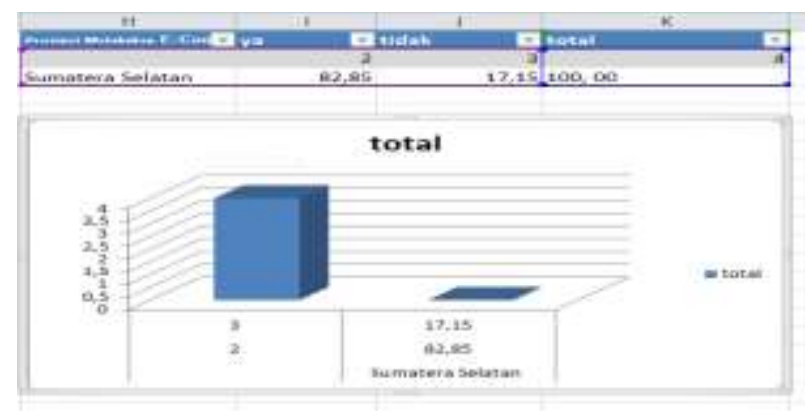

Gambar 4 : Diagram Batang

Dari hasil gambar diatas dapat dilihat adalah data dari provinsi Sumatera Selatan. Dimana formula dari proses Analisis data memberikan perhitungan dan pendeteksian data berupa diagram batang atau yang lainnya. Dari cara diatas data bisa dirubah sesuai dengan format data diatas, salah satunya dalam mencari informasi dari provinsi lain hanya dengan mencari data dan hasil akan keluar dengan sendirinya.

\section{KESIMPULAN}

Big data analytica (BDA) memberikan nilai bisnis pada perusahaan dalam berbagai cara dan banyak ahli mulai menyoroti perlunya memahami keunggulan kompetitif, dalam hal ini berkaitan dengan bagaimana memahami rantai nilai dari big data analytics. Ketersediaan data skala besar dan murah dewasa ini mendorong berbagai pihak untuk memanfaatkannnya melalui implementasi big data analytics. Peluang dan manfaat penerapan big data sangat potensial baik di organisasi bisnis maupun organisasi publik. Dengan menggunakan data, strategi bisnis maupun kebijakan publik bisa didesain dan diimplentasikan lebih efektif dan tepat untuk mencapai sasaran.

Dari hasil penelitian diatas dapat disimpulkan bahwa penggunaan Big Data Analystic dapat mempermudah pengusaha yang ada di indonesia. Dan Ecommerce yang ada dapat mewujudkan terciptanya smart city atau kota pintar di indonesia. Mengumpulkan data yang lebih akuran dan informasi yang jelas dalam mempermudah pengusaha dalam melihat hasil persentase setiap pembelian atau penjualan produck.

Maka dari itu hasil diatas sudah membuktikan bahwa penggunaan Big Data Analystic terbukti mampu memberikan data yang akurat dan informasi yang jelas terhadap penerapan E-Comerce di indonesia dalam membangun kota pintar di Indonesia saat ini.

\section{REFERENSI}

[1] Galuh Nurvinda Kurniawati 2020https://www.dqlab.id/big-data-analyticsdan-kegunaannya-untuk-perkembangan-bisnis

[2] Aberg, J., and Shahmehri, N. 2000. The Role of Human Web Assistants in E-Commerce: An Analysis and A Usability Study. Internet Research Electronic Networking Applications and Policy

[3] Hidayat, Taufik. 2008. Panduan Membuat Toko Online dengan OSCommerce, Jakarta : Mediakita

https://media.neliti.com/media/publications/865 12-ID-none.pdf

[4] 2016. Smart City [Online] Available at: https://en.wikipedia.org/wiki/Sm art_city [Accessed 9 Oktober 2016]

[5] Deakin, Mark (2013-08-22). "From intelligent to smart cities". In Deakin, Mark. Smart Cities: Governing, Modelling and Analysing the Transition. Taylor and Francis. p. 15. ISBN 9781135124144.

[6] Strategi Pembangunan Smart City dan Tantangannya bagi Masyarakat Kota Chandra Eko Wahyudi Utomo1) dan Mochamad Hariadi2)

http://repository.unej.ac.id/bitstream/handle/123 456789/79312/4.\%20Chandra.pdf?sequnce $=1 \&$ isAllowed=y oktober 2016

[7] Anggraini, Elisabet Yunaeti, And Ratnasari. "Perancangan Aplikasi E-Commerce Pada Toko Jam Tangan Alexander." Jurnal TAM (Technology Acceptance Model) 2 (2017). : 20 25.

[8] Lemieux, V. L., et.,al. (2014). Meeting big data challenges with visual analytics the role of records management. Records Management Journal, 24(2), 122-141. doi:10.1108/RMJ-01-2014-0009

[9] Emmelhainz, C. (2015). Data librarians in public Libraries. Retrieved from http://databrarians.org/author/celia/

[10] Putrawan, N. (2015). Relevansi big data dan ilmu perpustakaan: Sebuah pendekatan. 
Retrieved

from

https://www.linkedin.com/pulse/relevansi- bigdata-dan-ilmu-

perpustakaan-sebuah-baru-a-putrawan

[11] Abbasi, A., Sarker, S., Chiang, R.H.L., 2016. Big data research in information systems: toward an inclusive research agenda. J. Assoc. Inf. Syst. $17,1-32$.

[12] Agarwal, R., Dhar, V., 2014. Editorial-big data, data science, and analytics: the opportunity and challenge for IS research. Inf. Syst. Res. 25, 443-448.

[13] Alamsyah, A. (2015). (Big) Data Analytics for Economics, Business and Management: A Social Network Approach. In Workshop Big Data Puslitbang Aptika dan IKP,tanggal $19 \mathrm{Mei}$ 2015. Puslitbang Aptika dan IKP.

[14] Aryasa, K. (2015). Big Data: Challenges and Opportunities. In Workshop Big Data Puslitbang Aptika dan IKP, tanggal 19 Mei 2015. Puslitbang Aptika dan IKP.

[15] Bryant, R.E., Katz, R.H., Lazowska, E.D., 2008. Big-data computing: creating revolutionary breakthroughs in commerce, science, and society computing. Computing Research Initiatives for the 21st Century. Computing Research Association (Available at http://www.cra.org/ccc/files/docs/init/Big_Data. pdf).

[16] Chandarana, Parth, \& Vijayalakshmi, M. (2014). Big Data analytics frameworks: Circuits, Systems, Communication and Information Technology Applications (CSCITA). In International Conference on IEEE 2014. IEEE.

[17] Chen, H., Chiang, R., \& Storey, V. (2012). Business intelligence and analytics: From Big Data to big impact. MIS Quarterly, 36(4), 11651188.

[18] Chrisvania, N. (2017). Social media and technology's impact on business, society, and culture.

https://socialmediaweek.org/jakarta/2017/01/06 /strategi-dalam-implementasi-big-data/.

[19] Constantiou, I.D. and Kallinikos, J., 2015. "New games, new rules: big data and the changing context of strategy", Journal of Information Technology (30:1), pp.44-57.

[20] Corte Real,N., Oliveira, T., \& Ruivo, P. (2014). Understanding the hidden value of business intelligence and analytics (BI\&A). Twentieth American Conference of Information Systems. Savannah, Georgia: Association of Information Systems.

[21] Davenport, T.H., 2006. "Competing on analytics”, Harvard Business Review (84:1), p.98.

[22] Erevelles, S., Fukawa, N., \& Swayne, L. (2016). Big Data consumer analytics and the transformation of marketing. Journal of Business Research, 69(2), 897-904.

[23] Gartner, 2014. Gartner SaysWorldwide IT Spending on Pace to Grow 3.2 Percent in 2014.
[24] Gupta, M. and George, J.F., 2016. "Toward the development of a big data analytics capability", Information \& Management (53:8), pp.10491064. Janssen

[25] Kaisler, S., Armour, F., Espinosa, J.A. and Money, W., 2013. "Big data: Issues and challenges moving forward", in System sciences (HICSS), 2013 46th Hawaii international conference on (pp. 9951004). IEEE

[26] Kamioka, T. and Tapanainen, T., 2014. "Organizational Use of Big Data and Competitive AdvantageExploration of Antecedents", in PACIS 2014: 18th Pacific Asia Conference on Information Systems. Association for Information Systems. AIS Electronic Library (AISeL) (p. 372).

[27] Kwon, O., Lee, N., \& Shin, B. (2014). Data qualitymanagement, data usage experience and acquisition intention of Big Data analytics. International Journal of Information Management, 34(3), 387-394.

[28] Lavalle, S., Lesser, E., Shockley, R., Hopkins, M.S., Kruschwitz, N., 2011. Big data,analytics and the path from insights to value. Mit. Sloan Manag. Rev. 52, 21-32.

[29] McAfee, A., Brynjolfsson, E., Davenport, T.H., Patil, D.J. and Barton, D., 2012. "Big data. The management revolution", Harvard Business Review (90:10), pp.61-67.

[30] Morabito, V. (2015). Big Data and analytics: Strategic and organizational impacts. Springer.

[31]Rainer, Kelly, R., \& Cegielski., C. G. (2009). Introduction to Information Systems. John Wiley \& Sons (Asia) Pte Ltd.

[32] Russom, P. (2011). The Three Vs of Big Data Analytics. TDWI

[33] Shang, S., Seddon, P.B., 2002. Assessing and managing the benefits of enterprise system: The business manager perspective. Inf. Syst., J. 12 (4), 271-299.

[34] Wamba, S.F., Gunasekaran, A., Akter, S., Ren, S.J.F., Dubey, R. and Childe, S.J., 2017. "Big data analytics and firm performance: Effects of dynamic capabilities", Journal of Business Research (70), pp.356-365.

[35] https://www.bps.go.id//publication/2015/03/13/ d6ab15d18c4be6c1217f05eb/pedoman-sistempencarian-kode-klasifikasi-online-untukpengguna-2015.html

[36] https://www.google.com/url?sa=t\&rct=j\&q=\&e $\mathrm{src}=\mathrm{s} \&$ source $=$ web $\& \mathrm{~cd}=\&$ ved $=2$ ahUKEwjitp2 wrPfzAhWy9nMBHV0sDQYQFnoECAUQAQ \&url=https $\% 3 \mathrm{~A} \% 2 \mathrm{~F} \% 2 \mathrm{Fojs}$.stiami.ac.id\%2Fin dex.php $\% 2$ Fbijak $\% 2$ Farticle $\% 2$ Fdownload $\% 2 F$ 199\%2F132\&usg=AOvVaw2d4bYHjomP2AyE CCK4UCtR

[37] https://youtu.be/kjqLR7D4Sa8 